\title{
Plasma Cell Gingivitis: A Case Report
}

\author{
Lamdari N, Pradhan S \\ Department of Dental surgery, Periodontology and Oral Implantology Unit, National Academy of Medical Sciences, Bir \\ Hospital, Kathmandu, Nepal
}

\section{ABSTRACT}

Plasma cell gingivitis is a rare benign condition of the gingiva of unknown etiology characterized by sharply demarcated erythematous and edematous gingiva often extending to the mucogingival junction. This is sometimes considered as a hypersensitive reaction. It presents clinically as a diffuse, erythematous and papillary lesion of the gingiva, which frequently bleeds with minimal trauma. The histological appearance consists of a dense infiltration of normal plasma cells separated by collagenous stroma, usually confined to free and attached gingiva. The lesion can be eliminated by identifying and avoiding the source of the allergen along with nonsurgical periodontal therapy. We report a 29-years-old female patient diagnosed clinically as plasma cell gingivitis and confirmed histologically. The patient gave history of herbal dentifrice for a period of one year. Nonsurgical periodontal therapies along with discontinuation of herbal dentifrice lead to remission of the condition within a month.

Keywords: Herbal dentifrices, non-surgical periodontal therapy, plasma cell gingivitis

\section{INTRODUCTION}

Plasma cell gingivitis (PCG) is a rare benign inflammatory condition of gingiva of unknown etiology ${ }^{1,2}$ characterized by diffuse and massive infiltration of plasma cells into the sub-epithelial gingival tissue. ${ }^{3}$ The classical presentation of PCG includes painless, diffuse, erythematous and papillary lesion of the gingiva with a sharp demarcation along the mucogingival border, which frequently bleeds with minimal trauma. ${ }^{4}$ It is more prevalent in young women. ${ }^{5,6}$ Plasma Cell Gingivitis is also known by a variety of other names such as atypical gingivostomatitis, ${ }^{1}$ idiopathic gingivostomatitis, allergic gingivostomatitis, soft tissue plasmacytosis, stomatitis venenata or irritant contact stomatitis. Though the exact etiology is not known, allergic reaction seems to be a plausible explanation. ${ }^{7}$ It is also believed to be a hypersensitivity reaction to some antigen, often flavoring agents or spices. ${ }^{2,8}$

Plasma Cell Gingivitis mimics lesions associated with discoid lupus, lichen planus, cicatricial Pemphigoid, HIV-related gingivitis, leukemia and myeloma, thus an early diagnosis in such cases is vital in patient's interest. ${ }^{1,2,3,8,9}$ The diagnosis of PCG requires hematological screening in addition to clinical and histopathological examinations. ${ }^{1,2,10}$ Plasma Cell Gingivitis is purely benign, and the detection and elimination of the exposure to the etiologic antigenic agent will bring about the remission of the condition. ${ }^{10}$

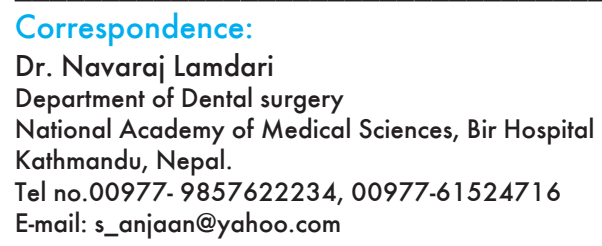

E-mail: s_anjaan@yahoo.com 


\section{CASE REPORT}

A 29-years-old female presented to the department of Dental surgery, Bir Hospital with chief complaints of red and swollen gums, bad breath and bleeding from gums during tooth brushing for one year duration. On examination there was severe inflammation of the gingival tissues from the free gingival margin to the mucogingival junction in both the maxillary and mandibular arches (Figure 1). Plaque accumulation was present around the teeth, and gingival bleeding occurred with the slightest provocation. There was a negative Nikolsky sign (blister formation) with no cutaneous lesion. Patient had neither any medical history nor reported a history of mouth breathing or the use of chewing gum.

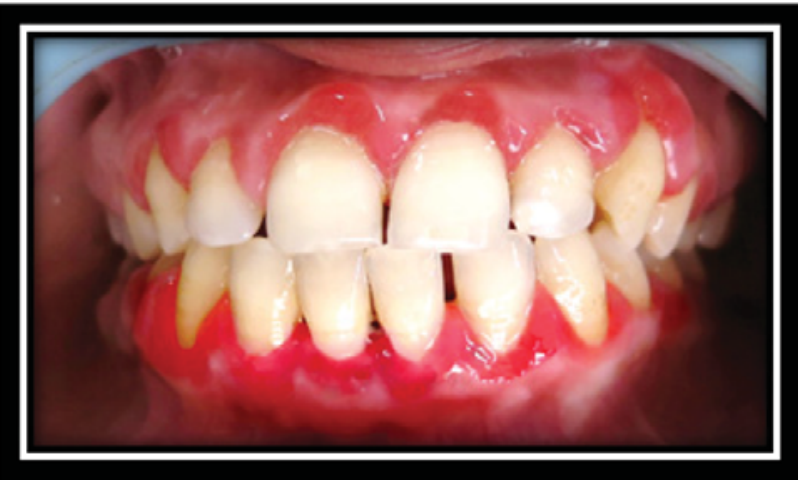

Figure 1. Red and swollen gingiva

Provisional diagnosis of chronic generalized gingivitis was made. The patient was treated with scaling, root planing and was asked to maintain oral hygiene. Patient was also instructed to rinse with $0.2 \%$ chlorhexidine twice daily. The appearance of the gingiva improved slightly after nonsurgical periodontal therapy, but was still severely erythematous (Figure 2).

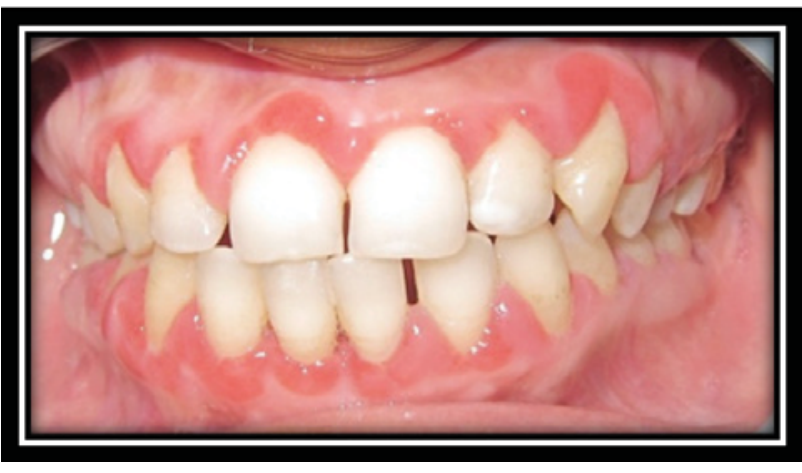

Figure 2. Four weeks after mechanical debridement

The erythema was disproportionate to the amount of plaque and calculus remaining on the dentition. Since the removal of local etiologic factors did not resolve the gingivitis, a decision was made to biopsy the affected tissue and to get the hematological tests done. Laboratory parameters were within normal limits and HIV serology was also negative.

Biopsy sample was obtained from the gingiva of the maxillary left canine and was processed for histopathological examination. The histopathological report revealed stratified squamous epithelium showing an edematous pseudo hyperplasia. The underlying connective tissue stroma displayed fibrocellular tissue composed of densely infiltrated chronic inflammatory cells chiefly of plasma cells and lymphocytes and abundant endothelium lined blood capillaries (Figure 3).

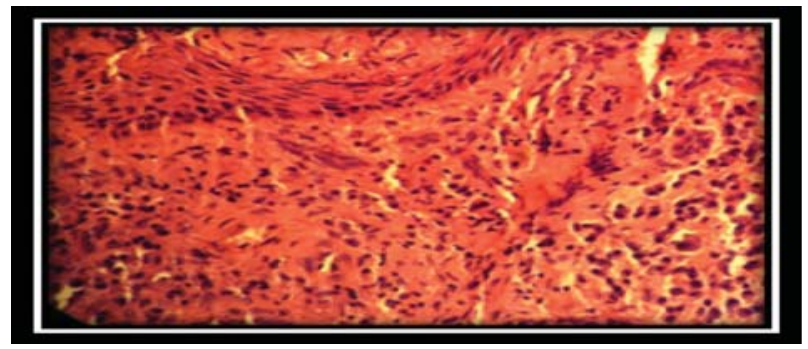

Figure 3. High power photomicrograph shows composed predominate of plasma cells

At high power the plasma cells were seen abundantly throughout the stroma, having hyperchromatic, cart wheel shaped nuclei. A diagnosis of plasma cell gingivitis was made.

Retrospective history taking disclosed that the patient was using herbal toothpaste since last one year. The patient was advised to discontinue the herbal toothpaste and nonsurgical periodontal therapy along with strict oral hygiene instructions were repeated resulting in dramatic improvement in the condition. After four weeks, the lesion had regressed to large extent (Figure 4).

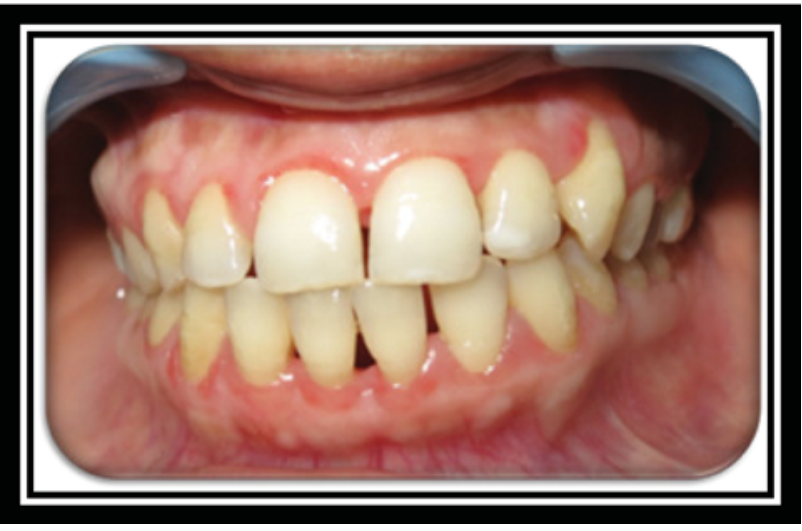

Figure 4. After 4 weeks of periodontal therapy and refraining from use of herbal tooth paste 


\section{DISCUSSION}

Plasma cell gingivitis is a rare condition characterized by diffuse and massive infiltration of plasma cells into the connective tissue. ${ }^{2}$ Clinically, the condition presents as a diffuse reddening together with edematous swelling of the gingiva, with sharp demarcation along the mucogingival border. ${ }^{1-6} \mathrm{~A}$ tendency for gingival bleeding upon tissue manipulation is invariably present in all cases. Ulceration is rare in the pathologically changed gingiva. The etiology of PCG is not clear, but due to the obvious presence of plasma cells many authors are of the opinion that it is an immunological reaction to allergens; these latter may occur in toothpaste, chewing gum, mint pastels and certain foods. It has been suggested that the strong spices and some herbs such as chili, pepper and cardamom may be important factors. Kerr et $\mathrm{al}^{9}$ reported a case of PCG or Plasmacytosis of the gingiva resulting from an allergic reaction to one of the constituents of chewing gum. Flavoring agents such as cinnamonaldehyde and cinnamon in chewing gums and dentifrices were also shown as etiologic factors in the development of PCG. Francis G Serio et $\mathrm{al}^{8}$ outlinrd a case of plasma cell gingivitis by the use of red peppers in cooking. Etiology of PCG has also been attributed to allergen, neoplastic and idiopathic by some authors. ${ }^{2}$

The diagnosis requires haematological screening in addition to clinical and histopathological examination. The differential diagnosis of the condition is very important because of its similarity with other aggressive conditions. Most cutaneous disorders were eliminated from consideration by the lack of skin lesions and a negative Nikolsky sign. The hematological tests were within the normal range. However, the patient's failure to respond appropriately to initial periodontal therapy necessitated a biopsy of the involved tissue. The histopathological picture revealed replacement of underlying connective tissue by a population of cells predominantly made up of plasma cells thus indicating the diagnosis. Once the diagnosis of Plasma Cell Gingivitis is made, the screening for the various antigenic substances should be done. In this case the only relevant history patient gave was the use of herbal toothpaste (allergen in this case). So the patient was advised to refrain from the use of herbal toothpaste and follow the oral hygiene instructions along with nonsurgical periodontal therapy which had undergone remission after four weeks of discontinuation of herbal toothpaste.

The case presented here highlights the adverse effects and irrational use of herbal dentifrices. As more and more herbal products are gaining popularity, clinicians should be aware of some of the untoward effects of these products.

\section{REFERENCES}

1. Sukumaran A. Plasma cell gingivitis among herbal toothpaste users: A report of three cases. J Contemp Dent Pract. 2007;8,4:60-66.

2. Vaidya P, Gupta U. Plasma cell gingivitis - A case report. Indian Journal of Dental Sciences. 2010; 2,2:23-25.

3. Marker P, Krogdahl A. Plasma cell gingivitis apparently related to the use of khat: Report of a case. Br Dent J. 2002; 192,6:311-313.

4. Patil S, Mehkri S, Lyenger AR, Nagesh KS, Kale K.Localised plasma cell gingivitis: a case report. SRM University Journal of Dental Sciences. 2010;1,1:130-133.

5. Shafer WG, Hine MK, Levy BM. Shafer's Textbook of Oral Pathology. $5^{\text {th }}$ Edition. Philadelphia, W.B. Saunders, 2006, p. 546.

6. Shruthi S., Gujjari SK, Hegde U, Kumar VSC. Unusual clinical presentation of a case of localized plasma cell gingivitis. Journal of Clinical and Diagnostic Research. 2011; 5,5:1125-1127.
7. Bonifazi E, Mazzotta F. Plasma cell gingivitis in a 10-year-old girl. Eur. J. Pediat. Dermatol. 2010; 20: 278.

8. Serio FG, Siegel MA, Slade BF. Plasma cell gingivitis of unusual origin. J Periodontol. 1991; 62: 390-393.

9. Kerr DA, McClatchey KD, Regezi JA. Idiopathic gingivostomatitis. Cheilitis, glossitis, gingivitis syndrome; atypical gingivostomatitis, plasma-cell gingivitis, plasmacytosis of gingiva. Oral Surg Oral Med Oral Pathol. 1971; 32,3:402-423.

10. Dhalla N, Narula IS, Patil SS. Plasma Cell Gingivitis - A Rare Case Report. JIDA. 2011;5,12:1230-1231.

11. Lamey PJ, Lewis MA, Rees TD, Fowler C, Binnie WH, Forsyth A. Sensitivity reaction to the cinnamonaldehyde component of toothpaste. Br Dent J.1990; 168(3):115-118.

12. Gargiulo A V, Ladone J A, Ladone P A, Toto P D. Case report: Plasma cell gingivitis A. CDS rev.1995; 88: 22-23.

13. Lubow RM, Cooley RL, Hartman KS, McDaniel RK. Plasma-cell gingivitis. Report of a case. J Periodontol 1984; 55,4:235-241 